\title{
Modulation of Platelet-derived Growth Factor Receptor Expression in Microvascular Endothelial Cells during In Vitro Angiogenesis
}

\author{
Martin Marx, Robin A. Perlmutter, and Joseph A. Madri \\ Department of Pathology, Yale University School of Medicine, New Haven, Connecticut 06510
}

\begin{abstract}
Microvascular endothelial cells in vivo exhibit a plastic phenotype, forming a nonproliferative, differentiated capillary network, while retaining their ability to respond to injury by proliferation, migration and neovascularization. The presence of PDGF receptors and PDGF responsiveness in microvascular endothelial cells and the significance of PDGF isoforms in the control of endothelial cell growth and differentiation remain controversial. Since culture of microvascular endothelial cells in a three-dimensional (3D) system induced cell differentiation and angiogenesis and inhibited proliferation, the present study investigates the role of different extracellular matrix environments in inducing different microvascular endothelial cell phenotypes on microvascular endothelial cell PDGF receptor expression and PDGF responsiveness. In conventional two-dimensional (2D) culture, microvascular endothelial cells expressed both PDGF receptor $\alpha$ and $\beta$ chains. Suramin treatment demonstrated continuous downregulation of the $\alpha$ receptor surface expression. PDGF BB and, to a lesser extent, PDGF AB were mitogenic in 2D-culture, PDGF AA failed to induce any proliferative response despite inducing receptor autophosphorylation. During in vitro angiogenesis induced by 3Dculture, both PDGF receptors were rapidly downregulated. Assessment of cell proliferation showed quiescent cells and PDGF unresponsiveness. We conclude that the induction of a differentiated phenotype during in vitro angiogenesis (tube formation) driven in part by the spatial organization of the surrounding matrix is associated with a downregulation of PDGF receptors. Identification of the molecular cell-matrix interactions involved in this receptor regulation may allow for targeted manipulation of cell growth in vivo and lead to novel therapeutic applications for PDGF. (J. Clin. Invest. 1994. 93:131-139.) Key words: microvascular endothelial cells $\bullet$ angiogenesis $\bullet$ plateletderived growth factor receptors $\bullet$ extracellular matrix • phenotypic modulation
\end{abstract}

\section{Introduction}

Interactions of microvascular endothelial cells with extracellular matrix components, neighboring cells, and responsiveness to autocrine and paracrine growth factors play pivotal roles during embryonic development of the vascular system and in

Address correspondence to Martin Marx, M.D., and Joseph A. Madri, Ph.D., M.D., Department of Pathology, LH 111, Yale University School of Medicine, 310 Cedar St., New Haven, CT 06510.

Received for publication 31 December 1992 and in revised form 26 July 1993

J. Clin. Invest.

(C) The American Society for Clinical Investigation, Inc.

$0021-9738 / 94 / 01 / 0131 / 09 \$ 2.00$

Volume 93, January 1994, 131-139 the maintenance of normal capillary structure and function. Disturbances in the complex regulatory systems controlling microvascular cell growth and differentiation may induce cell proliferation and neovascularization in several pathologic conditions such as wound healing, inflammation, and tumor angiogenesis. Microvascular endothelial cell invasion, proliferation, sprout development, and finally capillary tube formation during angiogenesis demonstrate the plasticity of the microvascular endothelial cell phenotype in response to extracellular matrix components and growth factors. PDGF is a candidate growth factor for autocrine and paracrine regulation of microvascular endothelial cell behavior. Previous work by others has demonstrated the expression of the PDGF A and B chain mRNAs in microvascular endothelial cells (1-3) and the level of expression is regulated by the action of proinflammatory factors such as TGF- $\beta$, thrombin, and agents that elevate cyclic AMP (4-7). In addition, during injury and inflammation the microvascular endothelial cells are exposed to PDGF released by platelets and other inflammatory cells. However, the presence of PDGF receptors and PDGF responsiveness of endothelial cells derived from different vascular beds remains controversial. The absence of PDGF receptors in cells derived from large vessels has been well established (8-10). On the other hand, microvascular endothelial cells from rat brain capillaries and from bovine and human adipose tissue have been shown to bind radiolabeled PDGF BB in tissue culture and to proliferate in response to PDGF $A B$ and $B B(9-11)$. We hypothesize that the reported controversies in endothelial cell $P D G F$ responsiveness may be caused in part by investigation of cells in distinct stages of differentiation and may reflect the phenotypic plasticity of microvascular endothelial cells. Previously, several groups have presented evidence that a variety of cells derived from different organ systems express a differentiated phenotype when cultured in a three-dimensional collagen gel. Namely, hepatocytes grown on floating collagen gels assume a trabecular, multicellular organization (12); mammary epithelial cells assume an acinar organization (13); Madin-Darby canine kidney cells form polarized cystlike structures when grown in type I collagen gels (14) and can be induced to form branching tubule-like structures when cocultured with fibroblasts (15). Since previous research has also demonstrated a remarkable plasticity of the microvascular endothelial cell phenotype driven by the composition and spatial organization of extracellular matrix (16-18), we investigated the effects of different extracellular matrix environments on PDGF $\alpha$ and $\beta$ receptor expression and PDGF responsiveness in microvascular endothelial cells and correlated these findings with endothelial cell differentiation and angiogenesis.

\section{Methods}

Cell culture. Microvascular endothelial cells from rat epididymal fat pads were isolated and cultured as previously described (19). The cells were generally used until passage 8 , and the cultures were split once per 
week at a 1:3 ratio. The maximum time in culture before use in experiments was $8 \mathrm{wk}$. For the investigation of PDGF receptor expression in two-dimensional culture, the cells were plated at a density of $10^{4} / \mathrm{cm}^{2}$ and analyzed after $24 \mathrm{~h}$ (subconfluent monolayer) or after $7 \mathrm{~d}$ of culture (confluent monolayer). Human plasma fibronectin, murine Engelbreth-Holm-Swarm tumor-derived laminin, calf dermal type I collagen (type I collagen $)^{1}$, Engelbreth-Holm-Swarm-derived type IV collagen (type IV collagen), and human placenta-derived type $\mathrm{V}$ collagen (type $V$ collagen) were prepared and purified as described (20-24). All matrix preparations have been shown to be endotoxin free (Coleman, D. L., and J. A. Madri, unpublished observation). For experiments in two-dimensional culture, bacteriologic plastic dishes (Falcon Labware, Oxnard, CA) were coated overnight at $4^{\circ} \mathrm{C}$ with matrix proteins dissolved in carbonate buffer ( $\mathrm{pH} 9.6)$. Protein-coating concentrations of $25 \mu \mathrm{g} / \mathrm{ml}$ (laminin) and $12.5 \mu \mathrm{g} / \mathrm{ml}$ (fibronectin and types I, IV, and V collagen) have been previously shown to be saturating (25). To study microvascular endothelial cells in a three-dimensional environment, gels composed of type I collagen were used. Briefly, type I collagen was solubilized overnight at $4^{\circ} \mathrm{C}$ in $10 \mathrm{mM}$ acetic acid to achieve a final type I concentration of $5 \mathrm{mg} / \mathrm{ml}$. The collagen was mixed with $10 \times$ Earle's salt (10:1), kept on ice, and neutralized with sterile $1 \mathrm{~N} \mathrm{NaOH}$. Immediately, the appropriate number of capillary endothelial cells was added to achieve a final concentration of $10^{6}$ cells $/ \mathrm{ml}$ collagen. $500 \mu \mathrm{l}$ of the cell/collagen mixture were transferred to 12-mm tissue culture inserts (Millicell HA or Anocell; Millipore Corp., Bedford, MA, and Anotec, Oxon, United Kingdom, respectively) and placed in 24-well cluster tissue culture dishes (Costar Corp., Cambridge, MA). The dishes were incubated for $10 \mathrm{~min}$ at $37^{\circ} \mathrm{C}$ to allow polymerization of the gels. Afterwards, $1.5 \mathrm{ml}$ of culture medium were added to each well. The equilibration time for macromolecules between two medium compartments separated by the collagen gel was previously determined to be $4 \mathrm{~h}$ using horseradish peroxidase type IV as an enzymatic marker (18). For morphological examination of 3D cultures, the collagen gels were washed three times with PBS, removed from the Millicell tissue culture inserts, and snap frozen in OCT embedding compound (Miles Scientific Co., Kankakee, IL). 6- $\mu \mathrm{m}$ cryostat sections of the gels were placed on albumin-coated glass slides, acetone fixed for $1 \mathrm{~min}$ at $-20^{\circ} \mathrm{C}$, and air dried. The sections were examined directly by Hofman interference or phase-contrast microscopy (IMT microscope and XP-2 film; Olympus Corp., Lake Success, NY, and Ilford Ltd., Basildon, Essex, United Kingdom, respectively).

Growth factors and antibodies. Recombinant PDGF AA, AB, and $\mathrm{BB}$, as well as a monoclonal phosphotyrosine antibody were purchased from Upstate Biotechnology (Lake Placid, NY). The polyclonal rabbit antiserum to a PDGF $\beta$ receptor cytoplasmic domain (26) was a generous gift of Dr. T. O. Daniel ( Vanderbilt University, Nashville, TN, and the rabbit antiserum to a cytoplasmic domain of the PDGF $\alpha$ receptor subunit was generously provided by Dr. J. A. Escobedo (University of California, San Francisco, CA). The rabbit polyclonal antibody to $\beta_{1}$ integrins was a gift of Dr. C. Buck (Wistar Institute, Philadelphia, PA).

Cell lysis and protein extraction. Cell cultures were chilled on ice and washed three times with cold PBS supplemented with protease inhibitors (see below). For the analyses of PDGF receptor expression by immunoblotting or immunoprecipitations from surface-labeled 2D cultures, the cells were removed from the petri dish using a Teflon scraper (Costar Corp.), centrifuged at 1,200 rpm for $5 \mathrm{~min}$, and the cell pellet resuspended in lysis buffer $(20 \mathrm{mM}$ Hepes, $1 \%$ Triton X-100, $20 \%$ glycerol, $2 \mathrm{mM}$ PMSF, $0.16 \mathrm{TIU} / \mathrm{ml}$ aprotinin, $2 \mathrm{mM}$ EGTA, 1 $\mathrm{mM}$ diisopropyl fluorophosphate, and $1 \mathrm{mM}$ leupeptin, all from Sigma Chemical Co., St. Louis, MO). Approximately $0.5-1 \times 10^{6}$ cells were lysed in $100 \mu \mathrm{l}$ lysis buffer. The resulting solution was spun $(12,000$ $\mathrm{rpm}$ for $10 \mathrm{~min}$ at $4^{\circ} \mathrm{C}$ ) and the supernatant was decanted and stored at

1. Abbreviations used in this paper: $2 \mathrm{D}$, two dimensional; 3D, three dimensional; TBS-T, TBS containing $0.05 \%$ Tween 20 ; type I collagen, calf dermal type I collagen; type IV, Engelbreth-Holm-Swarm tumorderived type IV collagen; type V collagen; human placenta-derived type I collagen. $-70^{\circ} \mathrm{C}$. For the investigation of PDGF receptor phosphorylation in 2D cultures, the cells were plated at a density of $10^{4} / \mathrm{cm}^{2}$. After $24 \mathrm{~h}$, the regular growth media was replaced by low serum media $(0.5 \% \mathrm{FCS})$ for $48 \mathrm{~h}$. Subsequently, the cells were treated with $20 \mathrm{ng} / \mathrm{ml}$ PDGF AA, $\mathrm{AB}$, or $\mathrm{BB}$ in serum free media for $15 \mathrm{~min}$ at $37^{\circ} \mathrm{C}$, control cultures received fresh media without PDGF. Proteins were extracted for 30 min at $4^{\circ} \mathrm{C}$ with radioimmunoprecipitation assay buffer ( $50 \mathrm{mM}$ Tris, pH 7.2, $150 \mathrm{mM} \mathrm{NaCl}, 1 \%$ Triton X-100, $1 \%$ sodium deoxycholate, and $0.1 \%$ SDS, all from Sigma Chemical Co.) in the presence of proteinase and phosphatase inhibitors ( $2 \mathrm{mM}$ PMSF, $1 \mathrm{mM}$ leupeptin, 0.16 trypsin inhibitor unit $/ \mathrm{ml}$ aprotinin, and $0.2 \mathrm{mM}$ vanadate). To extract proteins from cells grown in three-dimensional culture, the collagen gels were digested with $1 \mathrm{mg} / \mathrm{ml}$ collagenase type II (Sigma Chemical Co.) in PBS supplemented with $1 \mathrm{mM} \mathrm{CaCl}{ }_{2}$ and $1 \mathrm{mM} \mathrm{MgCl}_{2}$ at $37^{\circ}$ for $45 \mathrm{~min}$. This procedure yielded intact, viable cells that were pelleted and lysed as described above. In pilot experiments in 2D culture, it was shown that collagenase treatment did not destroy the PDGF receptor. The protein concentration in each lysate was determined spectrophotometrically (BCA protein assay reagent; Pierce Chemical Co., Rockford, IL).

Immunoprecipitations and immunoblot analyses. For each immunoprecipitation $300 \mu \mathrm{g}$ of extracted cell proteins were used. The cell lysates were preabsorbed with nonimmune IgG and protein G-Sepharose (Pharmacia, Uppsala, Sweden) for $60 \mathrm{~min}$ at $4^{\circ} \mathrm{C}$. Incubations with the primary antibodies were performed overnight at $4^{\circ} \mathrm{C}$ with gentle agitation. The antigen-antibody complexes were precipitated with 20 $\mu$ l of protein G-Sepharose, the beads pelleted and washed five times with radioimmunoprecipitation assay buffer. The extracted proteins from endothelial cell lysates were solubilized in 5× SDS loading buffer for $5 \mathrm{~min}$ at $100^{\circ} \mathrm{C}$ and separated by electrophoresis on $6 \%$ SDS-polyacrylamide gels (27) under reducing conditions. Subsequently, the proteins were transferred to a $0.45-\mu \mathrm{m}$ pore nitrocellulose membranes (Schleicher \& Schuell, Keene, NH) by electrophoresis (Polyblot; American Bionuclear, Emeryville, CA). Molecular weight markers and total protein were detected by staining with amido black. The nitrocellulose membranes were blocked (PBS/4\% BSA with $0.05 \% \mathrm{NaN}_{3}$ ) overnight at $4^{\circ} \mathrm{C}$. The membranes were washed three times in TBS-T $(0.05 \%$ Tween 20) in $50 \mathrm{mM}$ Tris, $150 \mathrm{mM} \mathrm{NaCl}$, and $0.05 \% \mathrm{NaN}_{3}, \mathrm{pH} 7.4$ ) and incubated with rabbit polyclonal or mouse monoclonal antibodies diluted 1:1,000 in PBS/4\% BSA for $2 \mathrm{~h}$ at room temperature with gentle agitation. Thereafter, the nitrocellulose was washed three times with TBS-T and incubated for $1 \mathrm{~h}$ at room temperature with an alkaline phosphatase-conjugated goat anti-rabbit or goat anti-mouse antibody (Promega Biotec, Madison, WI) diluted 1:7,500 in TBS-T. After three final washes, the nitrocellulose was incubated in alkaline phosphatase buffer ( $10 \mathrm{mM}$ Tris, $100 \mathrm{mM} \mathrm{NaCl}$, and $5 \mathrm{mM} \mathrm{MgCl}_{2}, \mathrm{pH}$ 9.5). Secondary antibody bound to the nitrocellulose was detected by incubation with a substrate solution (Sigma Chemical Co.), which consisted of nitroblue tetrazolium ( $330 \mu \mathrm{g} / \mathrm{ml})$ and 5-bromo-chloro-3-indolyl phosphate $(165 \mu \mathrm{g} / \mathrm{ml})$. The color development was stopped after $5 \mathrm{~min}$ by washing the nitrocellulose with $20 \mathrm{mM}$ Tris, $5 \mathrm{mM}$ EDTA, pH 8.0.

Cell surface labeling. Cells used for surface labeling in two-dimensional culture were plated at a density of $10^{4} / \mathrm{cm}^{2}$ in $60-\mathrm{mm}$ bacteriologic petri dishes coated with type I collagen and used as subconfluent monolayers. In some experiments, the cells were pretreated with 200 $\mu \mathrm{M}$ suramin (Mobay Chemical Co., New York) for $2 \mathrm{~h}$ before surface labeling. Subsequently, the cells were washed three times with PBS and treated with $1 \mathrm{mCi} / \mathrm{ml} \mathrm{Na}^{125} \mathrm{I}$ (Amersham Corp., Arlington Heights, IL, and New England Nuclear, Boston, MA) in PBS supplemented with $100 \mathrm{U} / \mathrm{ml}$ lactoperoxidase (Sigma Chemical Co.) and $0.005 \%$ hydrogen peroxide. The reaction was quenched after $10 \mathrm{~min}$ with repeated washes with excess cold $\mathrm{NaI}$ ( $20 \mathrm{mg} / \mathrm{ml}$ in PBS). To allow for surface labeling of endothelial cells in three-dimensional culture, the collagen gels were digested with collagenase, the cells were pelleted, and the surface was labeled as described for cells in two-dimensional culture. Cell lysates were prepared as described above and supplemented with $15 \mu \mathrm{l} 2 \mathrm{M} \mathrm{NaCl}, 10 \mu \mathrm{l} \mathrm{PBS} / 4 \% \mathrm{BSA}$, and $5 \mu \mathrm{l}$ distilled water/ 100 
$\mu 1$ lysate. The lysates were preabsorbed with $20 \mu$ l Sepharose CL-4B (Pierce Chemical Co.) with agitation for $60 \mathrm{~min}$ at $4^{\circ} \mathrm{C}$. The different rabbit polyclonal antisera were diluted $1: 25$ in PBS/4\% BSA, $50 \mu \mathrm{l}$ added to the preabsorbed lysate, and incubated for $90 \mathrm{~min}$ at $4^{\circ} \mathrm{C}$ with agitation. The antigen-antibody complexes were precipitated with $20 \mu \mathrm{l}$ of protein A-Sepharose (Pharmacia) for $90 \mathrm{~min}$ with gentle agitation. The antigen-antibody complexes bound to the Sepharose beads were pelleted in an Eppendorf microfuge and washed five times with $750 \mu \mathrm{l}$ of $50 \mathrm{mM}$ Tris, $150 \mathrm{mM} \mathrm{NaCl}, 0.5 \%$ sodium deoxycholate, $0.1 \% \mathrm{SDS}$, and $1 \%$ Triton $\mathrm{X}-100, \mathrm{pH} 7.5$. The proteins were solubilized by boiling the Sepharose beads for $5 \mathrm{~min}$ in $40 \mu \mathrm{l}$ of $2 \times$ SDS loading buffer and then electrophoresed on 6\% SDS-PAGE under reducing (PDGF receptors) or nonreducing (integrins) conditions. Gels were dried and exposed on film (XAR-5; Eastman Kodak, Rochester, NY) at $-70^{\circ} \mathrm{C}$. The relative density of specific bands was determined by scanning densitometry (Hoefer densitometer; Hoefer Scientific Instruments, San Francisco, CA).

Proliferation assays. To assess the cell proliferation in two-dimensional culture, $2 \times 10^{3}$ cells $/ \mathrm{cm}^{2}$ were plated on $35-\mathrm{mm}$ dishes coated with type I collagen. After $24 \mathrm{~h}$, the regular growth media was replaced by low serum media ( $2 \%$ FCS) for $24 \mathrm{~h}$. Subsequently, fresh low serum media supplemented with the appropriate concentrations of the PDGF isoforms were added. The cell number was determined after four additional days of culture. The cells were detached from the dishes using trypsin/EDTA, and the cell number counted in quadruplicate dishes for each condition using an automated cell counter (Coulter Electronics, Hialeah, FL). For the determination of mitogenic effects in threedimensional culture, the collagen gels were digested with collagenase, and the cells counted using a Coulter counter as described above.

Statistics. All data are presented as mean \pm SD. Differences between means were evaluated by the unpaired Student's $t$ test. In all circumstances, $P<0.05$ was considered significant.

\section{Results}

Spatial organization of extracellular matrix modulates the endothelial cell phenotype and induces angiogenesis. As previously described, microvascular endothelial cells placed in three-dimensional collagen gels underwent a dynamic re- sponse, spreading rapidly throughout the matrix, forming extremely elongated processes that establish physical contacts between single cells, forming a branching network (Fig. $1 b$ and $c$ ) $(18,28)$. This process was characterized by a rapid contraction of the collagen gels, which became visible after $\sim 8-12 \mathrm{~h}$ of culture. Morphologic analysis of frozen sections after $4 \mathrm{~d}$ (Fig. $1 \mathrm{~b}$ ) and $7 \mathrm{~d}$ (Fig. $1 \mathrm{c}$ ) of three-dimensional (3D) culture demonstrated that a network of tube like structures formed, which form lumina, resembling newly formed microvessels $(18,28)$. Microvascular endothelial cells grown in conventional two-dimensional culture express a very different phenotype (Fig. 1 a), forming a monolayer with no branching, tubelike structures detected, unless the cultures have been grown for a period of $\geq 2-3 \mathrm{wk}$ ( 18$)$.

$P D G F \alpha$ and $\beta$ receptors are expressed in microvascular endothelial cells and both are downregulated during in vitro angiogenesis. Analysis of the surface expression of the PDGF receptors in conventional two-dimensional culture demonstrated the presence of the PDGF $\beta$ receptor subunit in microvascular endothelial cells. When used in lysates from surface-labeled cells grown in $2 \mathrm{D}$, the $\beta$ receptor antibody precipitated two bands of 175 and $150 \mathrm{kD}$ (Fig. $2 a$, lane 1 ). The higher molecular weight band represents the mature receptor protein, the $150-\mathrm{kD}$ surface labeled protein coprecipitating with the PDGF $\beta$ receptor most likely corresponds to a previously described partially or nonglycosylated precursor form of the $\beta$ receptor (29) coexpressed on the cell surface. Since experiments with a variety of different proteases inhibitors showed identical results, it is unlikely that the $150-\mathrm{kD}$ band represents a proteolysis product. Analysis of the $\beta$ receptor surface expression in 3D culture revealed a rapid downregulation within $24 \mathrm{~h}$ (Fig. $2 a$, lane 2 ), compared to the $\beta$ receptor expression in cells grown for $24 \mathrm{~h}$ in two-dimensional (2D) culture (Fig. $2 a$, lane $1)$. The $\beta$ receptor subunit was almost completely lost on the cell surface after $6 \mathrm{~d}$ of 3D culture (Fig. $2 a$, lane 3). Fig. $2 b$
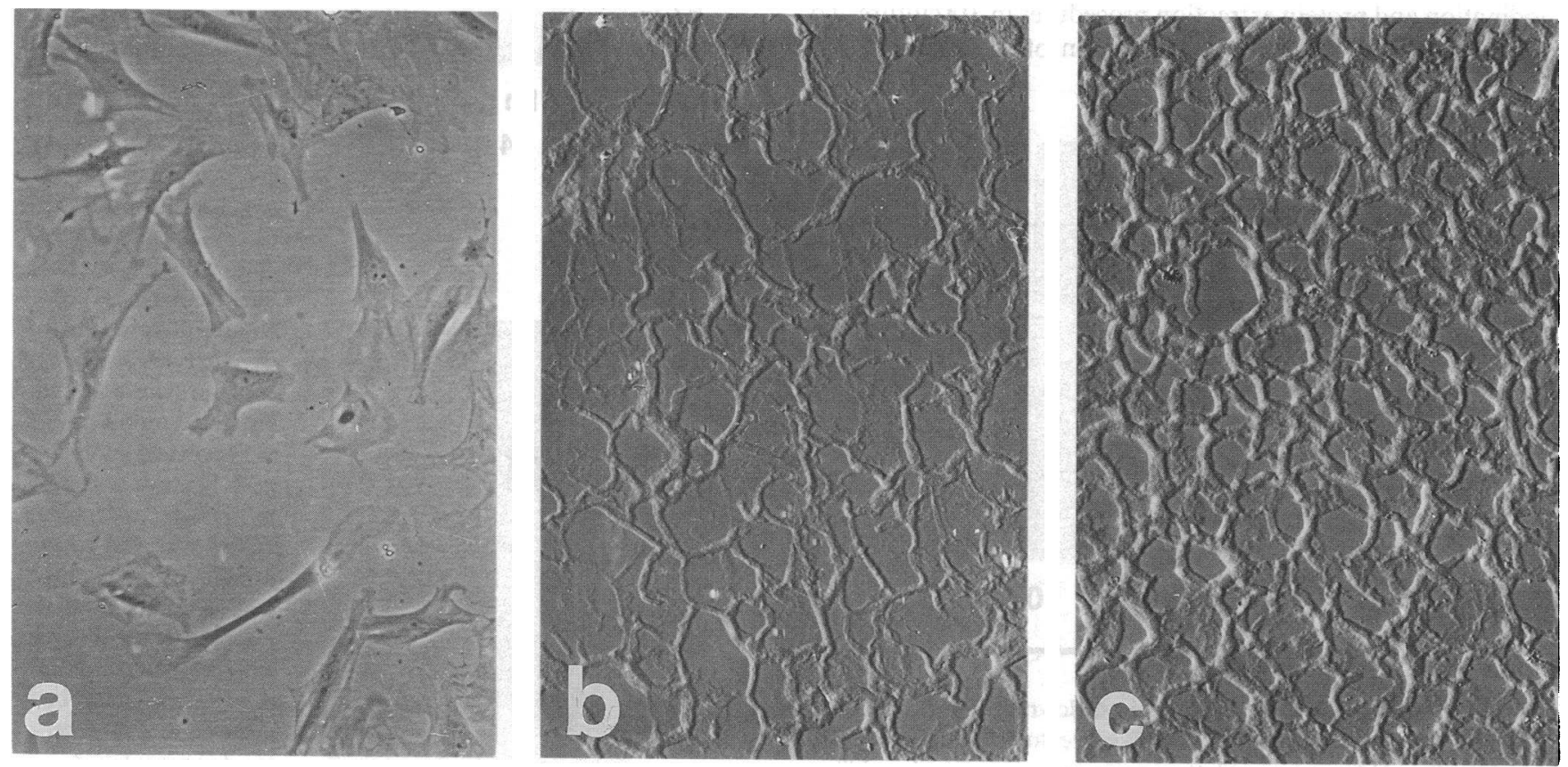

Figure 1. Three-dimensional culture in type I collagen gels induces a phenotypic change and angiogenesis. Microvascular endothelial cells in conventional two-dimensional culture form a monolayer without any organization (Fig. $1 a, \times 100$ ). Morphologic analysis after $4 \mathrm{~d}$ (Fig. $1 b$, $\times 100)$ and $7 \mathrm{~d}($ Fig. $1 c, \times 100)$ in 3D culture showed a branching network of newly formed microvessels. 
a

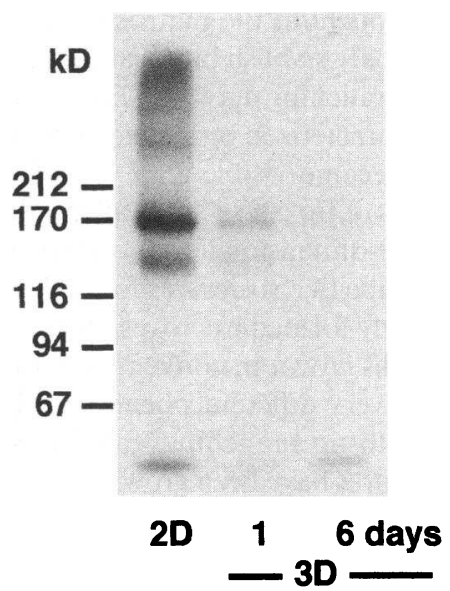

b

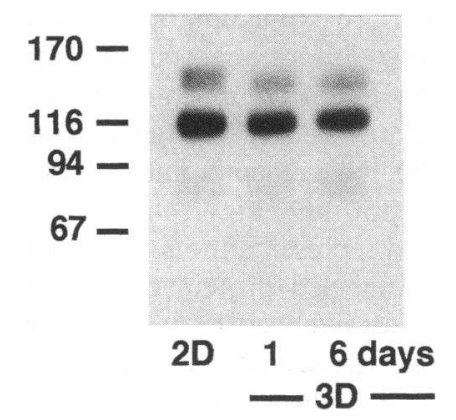

Figure 2. Three-dimensional culture downregulates the PDGF $\beta$ receptor. Microvascular endothelial cells were cultured on dishes coated with type I collagen $(2 D)$ or in three-dimensional type I collagen gels $(3 D)$. The PDGF $\beta$ receptor expression was analyzed on $6 \%$ SDS-PAGE by immunoprecipitation from ${ }^{125}$ I labeled cells after adjustment for total protein in the cell lysates. ( $a$ ) In 2D culture, the $\beta$ receptor antibody precipitated a strong $175 \mathrm{kD}$ (mature receptor) and $150 \mathrm{kD}$ (possible precursor protein) band. The surface expression of the $\beta$ receptor decreased rapidly after $1 \mathrm{~d}$ of $3 \mathrm{D}$ culture and was almost not detectable after $6 \mathrm{~d} .(b)$ The immunoprecipitation of $\beta_{1}$ integrins from the identical cell lysates served as control and showed no significant changes. The $\beta_{1}$ integrins correspond to the $115-\mathrm{kD}$ band, and the higher molecular weight band $(\sim 150 \mathrm{kD})$ represents the coprecipitated integrin $\alpha$ chains.

shows the unchanged surface expression of $\beta_{1}$ integrins precipitated as controls from the same cell lysates as the PDGF $\beta$ receptor, thus demonstrating the effectiveness of the surface iodination and protein extraction procedures in $3 \mathrm{D}$ culture. To address whether the reduced expression of the $\beta$ receptor is

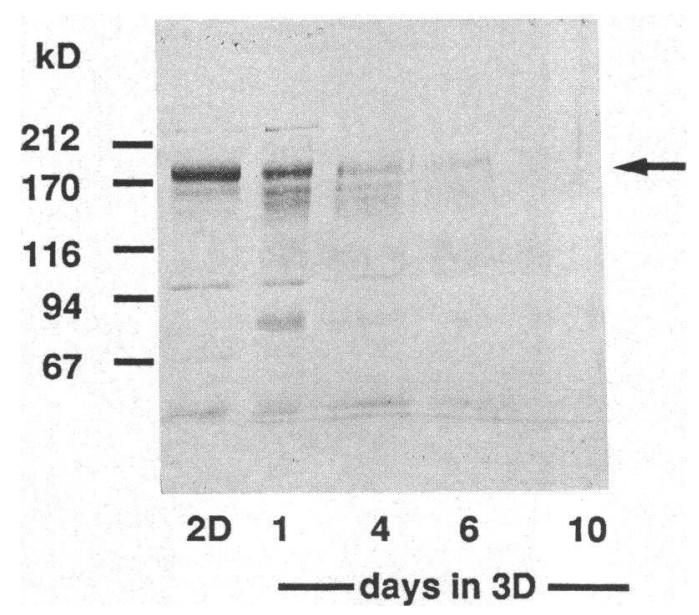

Figure 3. The PDGF $\beta$ receptor protein is downregulated during 3D culture. The time course of the PDGF $\beta$ receptor protein (arrow) was investigated by immunoblotting using lysates prepared at different time points (days $1,4,6$, and 10 ) of $3 \mathrm{D}$ culture and compared to cells grown in 2D culture. Equal protein loads were analyzed on each lane. caused by a reduced synthetic rate or to an accumulation of the receptor protein in the intracellular compartment, we investigated the time course of the $\beta$ receptor total protein expression in $3 \mathrm{D}$ culture by immunoblotting. Fig. 3 demonstrates a rapid downregulation of the $\beta$ receptor protein after the initiation of 3D culture, similar to the decrease in surface expression, thus confirming the notion that the downregulation of the $\beta$ receptor in $3 \mathrm{D}$ results from a reduction in total receptor protein, caused either by increased degradation or diminished synthesis. To demonstrate that the downregulation of the PDGF $\beta$ receptor is associated with the differentiation process driven by the spatial organization of the extracellular matrix in 3D culture and does not occur over the time course of 2D culture or as response to the composition of extracellular matrix in 2D culture (Fig. 4), the cells were grown on different extracellular matrix components (laminin, fibronectin, and type I, IV, and $\mathrm{V}$ collagen ), and the PDGF $\beta$ receptor expression was analyzed by immunoblotting after $24 \mathrm{~h}$ (Fig. $4 a$ ) and $7 \mathrm{~d}$ (Fig. $4 b$ ) of culture. No PDGF $\beta$ receptor downregulation could be observed after $7 \mathrm{~d}$ in $2 \mathrm{D}$ culture. In addition, no phenotypic modulation or changes in receptor expression could be detected in a

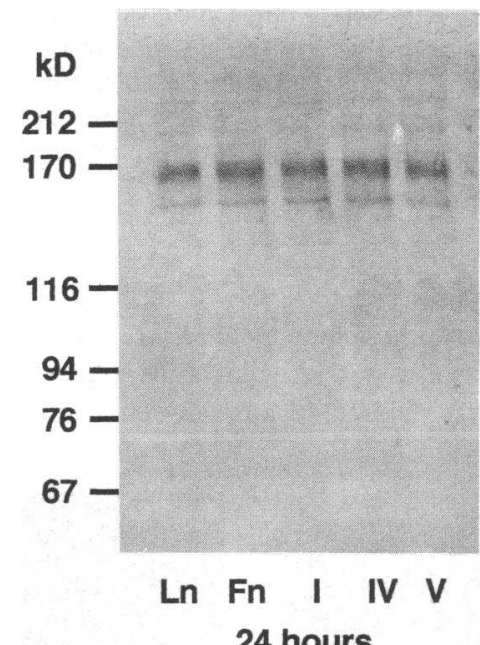

24 hours

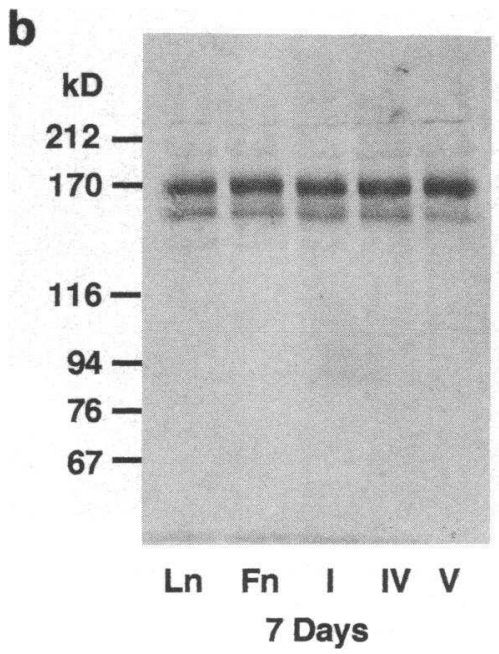

Figure 4. The PDGF $\beta$ receptor protein is not modulated by the composition of extracellular matrix during the time course of 2D culture. The cells were plated $\left(10^{4}\right.$ cells $\left./ \mathrm{cm}^{2}\right)$ on bacteriologic petri dishes coated with laminin $(L n)$, fibronectin $(F n)$, type I, IV, or V collagen. After 24 h (Fig. 4 $a$; subconfluent cultures) and after $7 \mathrm{~d}$ of culture (Fig. 4. $b$; confluent monolayer) of culture the proteins were extracted and equal protein amounts separated on $6 \%$ SDS-polyacrylamide gels. The expression of the PDGF $\beta$ receptor was investigated by immunoblotting. No modulation of the PDGF $\beta$ receptor by the different extracellular matrix components could be detected and no receptor downregulation ing the time course of 2D culture. could be observed dur- 
the cells grown on the different extracellular matrix components. Pilot experiments have shown that because of a trypsinsensible site in the ectodomain of the PDGF $\beta$ receptor, immediately after subculturing the cells by trypsinization, a major part of the 175-kD PDGF $\beta$ receptor is cleaved and shed from the cell surface, and only an $80-\mathrm{kD}$ tryptic product of the receptor can be detected by immunoblotting. However, the results of the 24-h experiment (Fig. $4 a$ ) clearly demonstrate reexpression of the mature $\beta$ receptor protein, and no tryptic product can be detected $24 \mathrm{~h}$ after trypsinization. Taken together, these data further support the notion of PDGF receptor regulation by the distinct spatial organization of matrix in 3D culture and its association with the phenotypic modulation of the cells during in vitro angiogenesis in 3D culture.

Analysis of the $\alpha$ receptor protein in 2D and during 3D culture by immunoblotting indicated the presence of this receptor subunit in capillary endothelial cells (Fig. 5). Only after prolonged 3D culture ( $10 \mathrm{~d}$ ) could a substantial downregulation of the $\alpha$ receptor protein be detected. Further investigation of the $\alpha$ receptor subunit surface expression by immunoprecipitation in 2D culture showed only a faint, barely detectable $190-\mathrm{kD}$ band (Fig. 6, lane 2). The $\alpha$ subunit was not detectable on the cell surface at any time point of $3 \mathrm{D}$ culture. Since we were able to precipitate the $\alpha$ receptor easily from surface-labeled smooth muscle cells (data not shown), it is unlikely that this result was caused by a low specificity of the antiserum.

The discrepancy between the low or nondetectable surface expression and the confirmation of the presence of the $\alpha$ receptor by immunoblotting prompted us to hypothesize either a predominantly intracellular localization of the $\alpha$ receptor in these cells and culture conditions or a rapid turnover of the cell surface receptors with quick internalization, even in the absence of exogenous PDGF. Since it has been shown that suramin binds to the PDGF receptor and prevents the interaction with its ligand and subsequent receptor internalization (30,

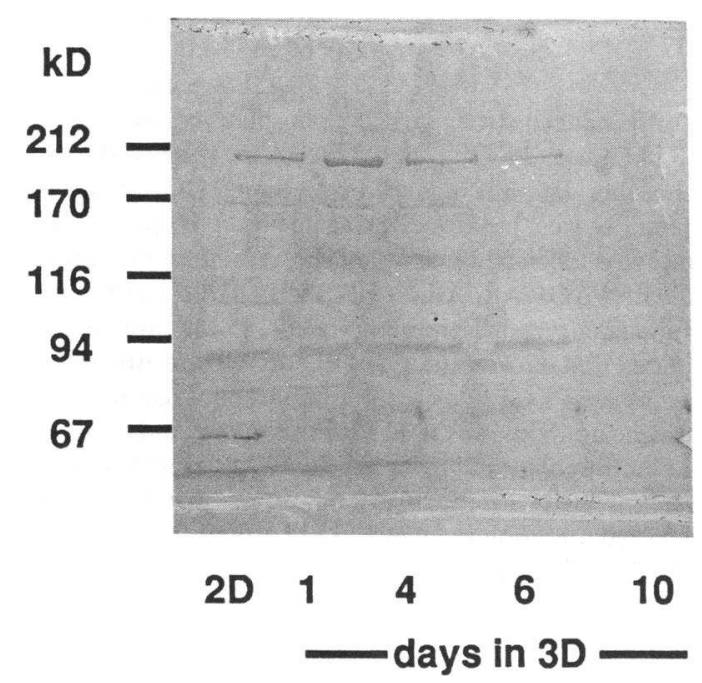

Figure 5. The PDGF $\alpha$ receptor protein is expressed in microvascular endothelial cells. The PDGF $\alpha$ receptor protein (arrow) was investigated by immunoblotting from cell lysates prepared from cells in 2Dculture and at different time points of 3D culture (days 1, 4, 6, and 10). Equal protein loads were analyzed on each lane. Downregulation of the $\alpha$ receptor protein could be detected after 6 and $10 \mathrm{~d}$ of $3 \mathrm{D}$ culture.

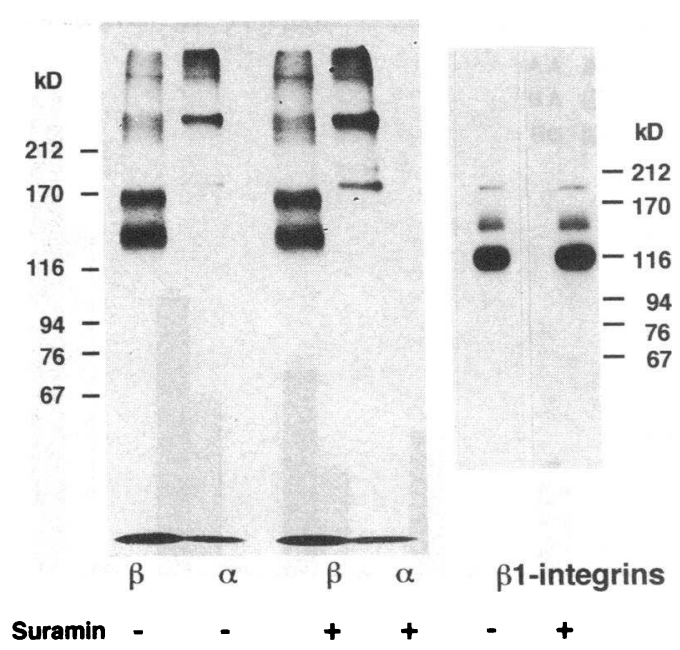

Figure 6. Suramin increases the PDGF $\alpha$ receptor surface expression. Lysates from ${ }^{125}$ I surface labeled cells grown in $2 \mathrm{D}$ culture were immunoprecipitated with the $\beta$ receptor (lanes 1 and 3 ) and $\alpha$ receptor antibody (lanes 2 and 4 ) and analyzed by SDS-PAGE under reducing conditions on $6 \%$ gels. Treatment with suramin (lanes 3 and 4 ) increased the $\alpha$ receptor expression on the cell surface 2.4-fold compared to nontreated cells (compare lanes 2 and 4 ). The surface expression of the $\beta$ receptor (compare lanes 1 and 3 ) and of $\beta_{1}$ integrins precipitated as controls (lanes 5 and 6 ) did not change.

31 ), we attempted to interrupt the suspected rapid internalization process of the $\alpha$ receptor by treatment with suramin. Fig. 6 shows the effect of the exposure of the capillary endothelial cells to $200 \mu \mathrm{m}$ suramin for $2 \mathrm{~h}$ : the surface expression of the $\alpha$ receptor (lane 4 ) increased dramatically compared to nontreated control cells (lane 2), whereas the expression of the $\beta$ receptor subunit (lanes 1 and 3 ) did not change. The intensity of the specific bands was quantified by scanning densitometry, normalized using the surface expression of $\beta_{1}$ integrins precipitated from the same cell lysates (lanes 5 and 6 ), and showed a suramin-induced 2.4-fold increase in the $\alpha$ receptor surface expression.

Functional significance of PDGF receptor expression and regulation in capillary endothelial cells during in vitro angiogenesis. In conventional two dimensional culture, both PDGF $\mathrm{AB}$ and $\mathrm{BB}$ induced a dose-dependent increase in cell number (Fig. 7). This effect was significant with both PDGF isoforms in a concentration as low as $1.25 \mathrm{ng} / \mathrm{ml}$. PDGF BB was a more potent mitogen compared to equivalent concentrations of PDGF AB. In contrast, even high concentrations $(20 \mathrm{ng} / \mathrm{ml})$ of the PDGF AA homodimer had no effect on capillary endothelial cell proliferation. This failure to induce any mitogenic response can not be attributed to a possible inability of PDGF AA to induce the formation of the $\alpha \alpha$ receptor homodimer. Analyses of PDGF $\alpha$ and $\beta$ receptor tyrosine phosphorylation demonstrated the induction of PDGF receptor autophosphorylation by all three PDGF isoforms (Fig. $8 a$ ). Furthermore, we could show specifically that PDGF $\alpha$ receptor autophosphorylation was induced by PDGF AA, AB, and BB (Fig. $8 b$ ), whereas only PDGF AB and BB induced PDGF $\beta$ receptor autophosphorylation (Fig. $8 c$ ). These data support the notion that dimerization and autophosphorylation of the $\alpha \alpha$ receptor occurs but may induce other than mitogenic signals in microvascular endothelial cells. Investigation of capillary endothelial cells in three-dimensional culture during in vitro angiogenesis 


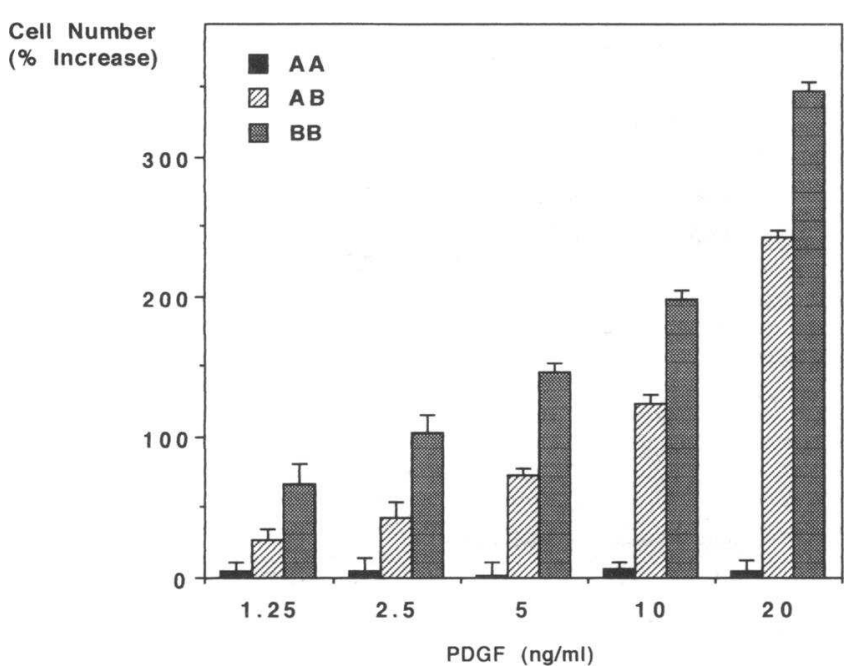

Figure 7. Mitogenic effects of PDGF AA, AB, and BB in microvascular endothelial cells in $2 \mathrm{D}$ culture. $2 \times 10^{3}$ cells $/ \mathrm{cm}^{2}$ were plated on collagen I coated dishes, made quiescent for $24 \mathrm{~h}$ in low serum media and stimulated with the three PDGF isoforms in the indicated concentrations for $4 \mathrm{~d}$. The cell number was determined using an automated cell counter and compared to the control experiment without PDGF. The data are given as mean \pm SD of quadruplicate dishes. PDGF $\mathrm{AB}$ and $\mathrm{BB}$ in all concentrations induced a significant increase in the cell number $(P<0.05)$ compared to controls.

revealed a rapid contraction of the collagen gels within 8-12 h and formation of tube- and capillary-like cellular structures within $2 \mathrm{~d}$. This process continued during $10-14 \mathrm{~d}$ and finally led to a dramatic contraction of the collagen gels to vol $<1$ $\mathrm{mm}^{3}$. Analysis of cell proliferation indicated an almost complete cell quiescence. Release of the capillary endothelial cells from the collagen gels by collagenase digest showed normal cell viability by trypan blue exclusion and replating in conventional two-dimensional culture induced a rapid proliferative response until confluency. Investigation of the mitogenic effects of the three PDGF isoforms in 3D culture failed to demonstrate any proliferative response (Fig. 9).

\section{Discussion}

Previous work investigating the complex process of angiogenesis and microvascular endothelial cell differentiation in vitro has demonstrated a remarkable plasticity of the microvascular endothelial cell phenotype in response to the composition and spatial organization of extracellular matrix ( for review, see references 32,33 ). Culture systems based on a three-dimensional ECM organization have been shown to induce microvascular endothelial cell differentiation, the formation of capillary-like structures (16-18), and inhibition of cell proliferation (28). In vivo microvascular endothelial cells retain the capability to modify their phenotype in response to injury, inflammation, or tumor angiogenic factors by disruption of the basement membrane, proliferation, and migration into the surrounding interstitial stroma and finally neovascularization. In human tumors, the density of newly formed microvessels has been shown to be a useful tool in the early detection of metastatic potential $(34,35)$. The spontaneous proliferation and respon- a



b
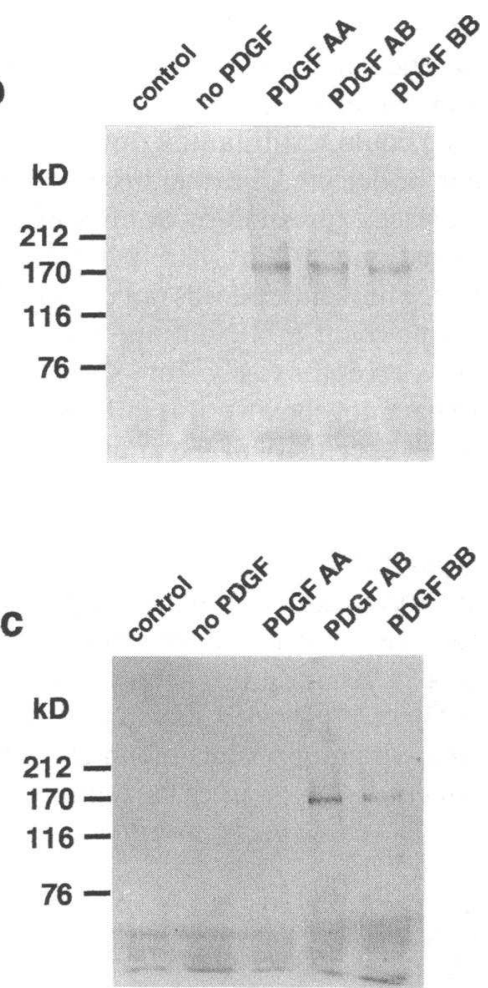

Figure 8. Differential effects of PDGF AA, $\mathrm{AB}$, and $\mathrm{BB}$ on PDGF $\alpha$ and $\beta$ receptor autophosphorylation in microvascular endothelial cells in 2D culture. Subconfluent cultures were made quiescent in low serum media $(0.5 \%$ FCS) for $48 \mathrm{~h}$ and subsequently treated with $20 \mathrm{ng} / \mathrm{ml}$ PDGF AA, $\mathrm{AB}$, or $\mathrm{BB}$ in serum free media for $15 \mathrm{~min}$ at $37^{\circ} \mathrm{C}$. Control cultures received only fresh media without PDGF. The proteins were extracted with RIPA buffer in the presence of proteinase and phosphatase inhibitors and $300 \mu \mathrm{g}$ protein were used for each immunoprecipitation as denoted below. Lane 1 shows always the immunoprecipitation with nonimmune IgG as negative control. (a) All three PDGF isoforms induce PDGF receptor autophosphorylation. Immunoprecipitation were performed with an antiphosphotyrosine antibody followed by antiphosphotyrosine immunoblot. Despite the lack of any mitogenic effect, PDGF AA induced tyrosine phosphorylation of a $185-\mathrm{kD}$ band, the PDGF $\alpha$ receptor.

PDGF $\mathrm{AB}$ and $\mathrm{BB}$ induced strong tyrosine phosphorylation of proteins of $175-185 \mathrm{kD}$, both PDGF $\alpha$ and $\beta$ receptors. (b) PDGF $\alpha$ receptor autophosphorylation is induced by all three PDGF isoforms. Immunoprecipitations were performed using an antibody specific for the PDGF $\alpha$ receptor followed by antiphosphotyrosine immunoblot. In cells treated with PDGF AA, AB, or BB, the PDGF $\alpha$ receptor antibody precipitated a tyrosine-phosphorylated $185-\mathrm{kD}$ protein, the autophosphorylated PDGF $\alpha$ receptor. (c) PDGF AB and BB, but not PDGF AA, induce PDGF $\beta$ receptor autophosphorylation. The antiphosphotyrosine antibody was used for immunoprecipitations and followed by immunoblotting using the PDGF $\beta$ receptor antibody. Only in cells treated with PDGF AB or BB, the PDGF $\beta$ receptor antibody detected a phosphorylated $175-\mathrm{kD}$ protein, the autophosphorylated PDGF $\beta$ receptor.

siveness to growth factors such as PDGF described in this report in vitro in conventional two-dimensional culture may reflect a microvascular endothelial cell behavior similar to the in vivo phenotype early in injury, inflammation, or tumor invasion in cells at or near the tip of the angiogenic sprout; while the behavior of the cells in 3D culture (including loss of PDGF 




etermined using an automated cell counter. The data are expressed as relative changes (in percentage) compared to control cultures without PDGF and given as means \pm SD of quadruplicate dishes.

receptors, responsiveness, and quiescence) may reflect a microvascular endothelial cell behavior similar to the in vivo phenotype observed in differentiating cells closer to the parent vessels and distal to the tips of the sprouts observed during angiogenesis $(25,36)$. Microvascular endothelial cells in vivo are considered not responsive to PDGF. However, recent research has demonstrated the presence of PDGF receptors in endotheliallike tumor cells (37), during tumor development and progression in endothelial cells in human gliomas $(38,39)$, in the vasculature of rheumatoid synovia (40), and PDGF responsiveness in microvascular endothelial cells was demonstrated in vitro in conventional two-dimensional culture (9-11). On the other hand, investigators have been unable to confirm the presence of both PDGF-receptors in differentiated and noninjured microvessels in vivo. These controversial results may well reflect the remarkable microvascular endothelial cell plasticity in response to injury and different culture conditions. Our results clearly demonstrate the presence of functional PDGF $\alpha$ and $\beta$ receptors in microvascular endothelial cells in two-dimensional culture. No modulation of PDGF $\beta$ receptor expression could be induced by changing the composition of extracellular matrix in 2D culture and no downregulation of the PDGF $\beta$ receptor was observed over the time course of 2D culture. Induction of microvascular cell differentiation and angiogenesis by the distinct organization of ECM in three-dimensional culture caused a rapid downregulation of the surface expression of the PDGF $\beta$ receptor, accompanied by growth arrest and nonresponsiveness to PDGF. Analysis of cells isolated from the 3D gels by collagenase digestion showed normal viability, rapid attachment, and spreading on conventional two-dimensional culture dishes, induction of proliferation to confluency, and PDGF responsiveness, thus demonstrating the reversibility of the differentiation process. Previous studies have demonstrated similar modulation of $\alpha$ smooth muscle actin expression in these cells (41). Specifically, we found that microvascular endothelial cells express $\alpha$ smooth muscle actin mRNA and protein when placed in 2D culture. When these cells were taken out of $2 \mathrm{D}$ culture and placed in $3 \mathrm{D}$ culture in collagen gels, the cells downregulated their expression of $\alpha$ smooth muscle actin. This specific behavior was reversible, in that removal of the cells from the $3 \mathrm{D}$ culture environment and placement in a 2D culture environment elicited reexpression of $\alpha$ smooth muscle actin. The cells retain their expression of Factor VIII-related antigen $(18,41)$ and their inducibility of ELAM-1 under both 2D and 3D culture conditions (Merwin, J. R., and J. A. Madri, unpublished observations), consistent with their endothelial phenotype.

Our studies have demonstrated a differential effect of the three PDGF isoforms on capillary endothelial cells in two-dimensional culture: PDGF AA has no mitogenic effect, $A B$ induces an intermediate response, and $\mathrm{BB}$ is the strongest mitogen. The failure of PDGF AA to induce any mitogenic response cannot be attributed to the low $\alpha$ receptor surface expression or to a lack of $\alpha$ receptor autophosphorylation. Our results in 2D culture have shown that PDGF AA induces tyrosine phosphorylation, despite the lack of any mitogenic effect, and the PDGF $\alpha$ receptor is autophosphorylated in response to all three PDGF isoforms. On the other hand, the PDGF $\beta$ receptor is autophosphorylated only by PDGF AB and BB. The incompletely glycosylated $150-\mathrm{kD}$ precursor form of the PDGF $\beta$ receptor detectable in the Western blots and immunoprecipitations from surface labeled cells is not autophosphorylated by PDGF treatment. Together with the analyses of the proliferation experiments, these results indicate that only the mature PDGF $\beta$ receptor and not the $\alpha$ receptor transduces mitogenic signals in microvascular endothelial cells in 2D culture. These results are in perfect accordance with the concept of isoform-specific association of both PDGF receptor subunits (42, 43): binding of PDGF to its receptor requires receptor dimerization and is restricted to ligand-specific association of the receptor subunits. PDGF AA binds only to the $\alpha \alpha$ receptor homodimer, $\mathrm{AB}$ to the $\alpha \alpha$ and $\alpha \beta$ receptors, and $\mathrm{BB}$ to all three possible receptor dimers $(\alpha \alpha, \alpha \beta$, and $\beta \beta)$. The mitogenic effects of PDGF AB and BB in 2D culture suggest the expression of both PDGF receptor subunits in microvascular endothelial cells. The reduced responsiveness of PDGF AB may be caused by the low surface expression of the PDGF $\alpha$ receptor, alternatively a reduced ligand binding affinity or differences in intracellular signal transduction are possible explanations. Since PDGF AA failed to induce any mitogenic effect despite tyrosine phosphorylation of the receptor and other signal transducing proteins and recent work indicating that PDGF AB is able to induce $\beta \beta$ receptor homodimers (44) and does not require $\alpha$ receptors for functional binding (45), we conclude that activation of the $\alpha$ receptor may induce other than mitogenic effects in microvascular endothelial cells. The very low surface expression of the $\alpha$ receptor in microvascular endothelial cells compared to smooth muscle cells prompted us to hypothesize a possible receptor downregulation by an autocrine PDGF loop, recently suggested in human glioblastoma (37) and smooth muscle cells (46). Treatment with suramin, which has been shown previously to bind to the PDGF receptor and to prevent its internalization $(30,31)$, induced a rapid increase of the surface expression of the $\alpha$ receptor subunit, suggesting receptor downregulation by endogenous PDGF AA. Regulation of PDGF receptor expression may play a pivotal role in the control of cell growth in response to injury or to angiogenic factors. Strategies aiming at the targeted modification of PDGF receptor expression may widen possible therapeutic applications of PDGF (47). TGF- $\beta$ has been shown to downregulate the $\alpha$ receptor and to upregulate the $\beta$ receptor $(46,48)$; both receptor subunits are upregulated by PDGF BB (49) and the $\beta$ receptor expression is elevated by increased cAMP $(50)$. The present 
report demonstrates PDGF receptor downregulation and growth arrest induced by the phenotypic modulation of microvascular endothelial cells in a three-dimensional environment. Specific inhibition of cell-cell and/or cell-matrix interactions using antibodies against selected cell adhesion molecules or matrix binding proteins or peptides resembling known binding regions in these moieties could prevent the differentiation process in $3 \mathrm{D}$ culture and may prove useful in delineating receptor-ligand pairs associated with the phenotypic change in $3 \mathrm{D}$ culture. Alternatively, experimental activation of these particular receptor ligand pairs in 2D culture may inhibit cell proliferation and induce differentiation, and thus lead to new therapeutic strategies in pathologic conditions associated with PDGF responsiveness and neovascularization. Furthermore, quantitative analyses of PDGF receptor expression in microvascular endothelial cells in tumor tissue specimens may prove to be a useful tool in the determination and assessment of angiogenic and metastatic potential.

\section{Acknowledgments}

We thank Dr. Clayton Buck for the generous gift of the $\beta_{1}$ integrin antiserum, Dr. T. O. Daniel for the PDGF- $\beta$ receptor antiserum, Dr. J. A. Escobedo for the PDGF- $\alpha$ receptor antibody, and Ms. Adeline Tucker and Ms. Susanne Voit for expert technical assistance.

This work was supported by grants $1225 / 1-1$ from the Deutsche Forschungsgemeinschaft (M. Marx) and PO1 DK-38979 and RO1 HL-28373 from the National Institutes of Health (J. A. Madri).

\section{References}

1. DiCorleto, P. E., and D. F. Bowen-Pope. 1983. Cultured endothelial cells produce a platelet-derived growth factor-like protein. Proc. Natl. Acad. Sci. USA. 80:1919-1923.

2. Barrett T. B., C. M. Gajdusek, S. M. Schwartz, J. K. McDougall, and E. P. Benditt. 1984. Expression of the sis gene by endothelial cells in culture and in vivo. Proc. Natl. Acad. Sci. USA. 81:6772-6774.

3. Collins, T., D. Ginsburg, J. M. Boss, S. H. Orkins, and J. S. Pober. 1985 Cultured human endothelial cells express platelet-derived growth factor B-chain: cDNA cloning and structural analysis. Nature (Lond.) 316:748-750.

4. Daniel, T. O., V. C. Gibbs, D. F. Milfay, M. R. Garovoy, and L. T. Williams. 1986. Thrombin stimulates c-sis gene expression in microvascular endothelial cells. J. Biol. Chem. 261:9579-9582.

5. Daniel, T. O., V. C. Gibbs, D. F. Milfay, and L. T. Williams. 1987. Agents that increase cAMP accumulation block endothelial c-sis induction by thrombin and transforming growth factor- $\beta$. J. Biol. Chem. 262:11893-11896.

6. Starksen, N. F., G. R. Harsh, V. C. Gibbs, and L. T. Williams. 1987. Regulated expression of the platelet-derived growth factor A chain gene in microvascular endothelial cells. J. Biol. Chem. 262:14381-14384.

7. Kavanaugh, W. M., G. R. Harsh, N. F. Starksen, C. M. Rocco, and L. T. Williams. 1988. Transcriptional regulation of the $A$ and $B$ chain genes of plateletderived growth factor in microvascular endothelial cells. J. Biol. Chem. 263:8470-8472.

8. Heldin, C.-H., B. Westermark, and A. Wasteson. 1981. Specific receptors for platelet-derived growth factor on cells derived from connective tissue and glia. Proc. Natl. Acad. Sci. USA. 78:3664-3668.

9. Bar, R. S., M. Boes, B. A. Booth, B. L. Dake, S. Henley, and M. N. Hart. 1989. The effects of platelet-derived growth factor in cultured microvessel endothelial cells. Endocrinology. 124:1841-1848.

10. Smits, A., M. Hermansson, M. Nister, I. Karnushina, C.-H. Heldin, B. Westermark, and K. Funa. 1989. Rat brain capillary endothelial cells express functional PDGF B-type receptors. Growth Factors. 2:1-8.

11. Beitz, J. G., I.-S. Kim, P. Calabresi, and A. R. Frackelton. 1991. Human microvascular endothelial cells express receptors for platelet-derived growth factor. Proc. Natl. Acad. Sci. USA. 88:2021-2025.

12. Michalopoulos, G., and H. C. Pitot. 1975. Primary culture of parenchymal liver cells on collagen membranes. Exp. Cell. Res. 94:70-78.

13. Emerman, J. T., and D. R. Pitelka. 1977. Maintenance and induction of morphological differentiation in dissociated mammary epithelium on floating collagen membranes. In Vitro Cell. \& Dev. Biol. 13:316-328.

14. Hall, H. G., D. A. Farson, and M. J. Bissell. 1982. Lumen formation by epithelial cell lines in response to collagen overlay: a morphogenetic model in culture. Proc. Natl. Acad. Sci. USA. 79:4672-4676.

15. Montesano, R., G. Schaller, and L. Orci. 1991. Induction of epithelial tubular morphogenesis in vitro by fibroblast-derived soluble factors. Cell. 66:697-711.

16. Delvos, U., C. Gajdusek, H. Sage, L. A. Harker, and S. M. Schwartz. 1982. Interactions of vascular wall cells with collagen gels. Lab. Invest. 46:61-72.

17. Nicosia, R. F., and J. A. Madri. 1987. The microvascular extracellular matrix: developmental changes during angiogenesis in the aortic ring-plasma clot model. Am. J. Pathol. 128:78-90.

18. Madri, J. A., B. M. Pratt, and A. M. Tucker. 1988. Phenotypic modulation of endothelial cells by TGF- $\beta$ depends upon the composition and organization of extracellular matrix. J. Cell Biol. 106:1375-1384.

19. Madri, J. A., and S. K. Williams. 1983. Capillary endothelial cell cultures: Phenotypic modulation by matrix components. J. Cell Biol. 97:153-165.

20. Roll, F. J., J. A. Madri, J. Albert, and H. Furthmayr. 1980. Codistribution of collagen types IV and $\mathrm{AB}_{2}$ in basement membranes and mesangium of the kidney: an immunoferritin study of ultrathin frozen sections. J. Cell Biol. 85:597-616.

21. Madri, J. A., F. J. Roll, H. Furthmayr, and J. M. Foidart. 1980. The ultrastructural localization of fibronectin and laminin in the basement membranes of the murine kidney. J. Cell Biol. 86:682-687.

22. Madri, J. A., and H. Furthmayr. 1980. Collagen polymorphism in the lung: an immunochemical study of pulmonary fibrosis. Hum. Pathol. 11:353366.

23. Madri, J. A. 1982. The preparation of type V (AB) collagen. In Immunochemistry of the Extracellular Matrix, Vol 1. H. Furthmayr, editor. CRC Press, Boca Raton, FL. pp. 75-89.

24. Yanariello-Brown, J., U. Wewer, L. Liotta, and J. A. Madri. 1988. Distribution of a $69 \mathrm{kD}$ laminin-binding protein in aortic and microvascular endothelial cells: modulation during cell attachment, spreading, and migration. J. Cell Biol. 106:1773-1786.

25. Form, D. M., B. M. Pratt, and J. A. Madri. 1986. Endothelial cell proliferation during angiogenesis: in vitro modulation by basement membrane components. Lab. Invest. 55:521-530.

26. Kumjian, D. A., M. I. Wahl, S. G. Rhee, and T. O. Daniel. 1989. Plateletderived growth factor (PDGF) binding promotes physical association of PDGF receptor with phospholipase C. Proc. Natl. Acad. Sci. USA. 86:8232-8236.

27. Laemmli, U. K. 1970. Cleavage of structural proteins during the assembly of the head of bacteriophage T4. Nature (Lond.). 227:680-685.

28. Merwin, J. R., J. M. Anderson, O. Kocher, C. M. van Itallie, and J. A Madri. 1990. Transforming growth factor $\beta_{1}$ modulates extracellular matrix organization and cell-cell junctional complex formation during in vitro angiogenesis. J. Cell. Physiol. 142:11-128.

29. Daniel, T. O., D. F. Milfay, J. Escobedo, and L. T. Williams. 1987. Biosynthetic and glycosylation studies of cell surface platelet-derived growth factor receptors. J. Biol. Chem. 262:9778-9784.

30. Garrett, J. S., S. R. Coughlin, H. L. Niman, P. M. Tremble, G. M. Giels, and L. T. Williams. 1984. Blockade of autocrine stimulation in simian sarcoma virus-transformed cells reverses down-regulation of platelet-derived growth factor receptors. Proc. Natl. Acad. Sci. USA. 81:7466-7470.

31. Williams, L. T., P. Tremble, M. F. Lavin, and M. E. Sunday. 1984. Platelet-derived growth factor receptors form a high affinity state in membrane preparations. J. Biol. Chem. 259:5287-5294.

32. Ingber, D. E., and J. Folkman. 1989. How does extracellular matrix control capillary morphogenesis? Cell. 58:803-805.

33. Montesano, R. 1992. Regulation of angiogenesis in vitro. Eur. J. Clin. Invest. 22:504-515.

34. Weidner, N., J. P. Semple, W. R. Welch, and J. Folkman. 1991. Tumor angiogenesis and metastasis: correlation in invasive breast carcinoma. $N$. Engl. $J$. Med. 324:1-8.

35. Horak, E. R., R. Leek, N. Klenk, S. LeJeune, K. Smith, N. Stuart, M. Greenall, K. Stepniewska, and A. L. Harris. 1992. Angiogenesis, assessed by platelet/endothelial cell adhesion molecule antibodies, as indicator of node metastases and survival in breast cancer. Lancet. 340:1120-1124.

36. Madri, J. A., M. Marx. 1992. Matrix composition, organization and soluble factors: Modulators of microvascular cell differentiation in vitro. Kidney Int. 41:560-565.

37. Werner, S., P. H. Hofschneider, C.-H. Heldin, A. Ostman, and W. K. Roth. 1990. Cultured Kaposi's sarcoma-derived cells express functional PDGF A-type and B-type receptors. Exp. Cell. Res. 187:98-103.

38. Hermansson, M., M. Nister, C. Betsholtz, C.-H. Heldin, B. Westermark and K. Funa. 1988. Endothelial cell hyperplasia in human glioblastoma: coexpression of mRNA for platelet-derived growth factor (PDGF) B chain and PDGF receptor suggests autocrine growth stimulation. Proc. Natl. Acad. Sci. USA. 85:7748-7752. 
39. Plate, K. H., G. Breier, C. L. Farrell, and W. Risau. 1992. Platelet-derived growth factor receptor- $\beta$ is induced during tumor development and upregulated during tumor progression in endothelial cells in human gliomas. Lab. Invest. 67:529-534.

40. Reuterdahl, C., A. Tingström, L. Terracio, K. Funa, C.-H. Heldin, and K. Rubin. 1991. Characterization of platelet-derived growth factor $\beta$-receptor ex pressing cells in the vasculature of human rheumatoid synovium. Lab. Invest. 64:321-329.

41. Kocher, O., J. A. Madri. 1989. Modulation of actin mRNAs in cultured capillary endothelial and aortic endothelial and smooth muscle cells by matrix components and TGF- $\beta 1$. In Vitro Cell. \& Dev. Biol. 25:424-434.

42. Hart, C. E., J. W. Forstrom, J. D. Kelly, R. A. Seiffert, R. A. Smith, R. Ross, M. J. Murray, and D. F. Bowen-Pope. 1988. Two classes of PDGF receptor recognize different isoforms of PDGF. Science (Wash. DC). 240:1529-1531.

43. Seiffert, R. A., C. E. Hart, P. E. Phillips, J. W. Forstrom, R. Ross, M. J. Murray, and D. F. Bowen-Pope. 1989. Two different subunits associate to create isoform-specific platelet-derived growth factor receptors. J. Biol. Chem. 264:8771-8778

44. Heidaran, M. A., J. H. Pierce, J.-C. Yu, D. Lombardi, J. E. Arttrip, T. P. Fleming, A. Thomason, and S. A. Aaronson. 1991. Role of $\alpha \beta$ receptor hetero- dimer formation in $\beta$ platelet-derived growth factor (PDGF) receptor activation by PDGF AB. J. Biol. Chem. 266:20232-20237.

45. Drozdoff, V., and W. J. Pledger. 1991. Cellular responses to platelet-derived growth factor (PDGF)-AB after downregulation of PDGF $\alpha$-receptors. $J$. Biol. Chem. 266:17165-17172.

46. Battegay, E. J., E. W. Raines, R. A. Seiffert, D. F. Bowen-Pope, and R. Ross. 1990. TGF- $\beta$ induces bimodal proliferation of connective tissue cells via complex control of an autocrine PDGF loop. Cell. 63:515-524.

47. Robson, M. C., L. G. Phillips, A. Thomason, L. E. Robson, and G. F. Pierce. 1992. Platelet-derived growth factor BB for the treatment of chronic pressure ulcers. Lancet. 339:23-25.

48. Gronwald, R. G. K. R. A. Seifert, and D. F. Bowen-Pope. 1989. Differential regulation of expression of two platelet-derived growth factor receptor subunits by transforming growth factor- $\beta$. J. Biol. Chem. 264:8120-8125.

49. Eriksson, A., M. Nister, P. Leveen, B. Westermark, C.-H. Heldin, and L. Claesson-Welsh. 1991. Induction of platelet-derived growth factor $\alpha$ - and $\beta$-receptor mRNA and protein by platelet-derived growth factor BB. J. Biol. Chem. 266:21138-21144.

50. Weinmaster, G., and G. Lemke. 1990. Cell-specific cyclic AMP-mediated induction of the PDGF receptor. EMBO (Eur. Mol. Biol. Organ.) J. 9:915-920. 